\title{
Favourable pregnancy outcome in a woman with secondary pulmonary hypertension complicating mitral stenosis
}

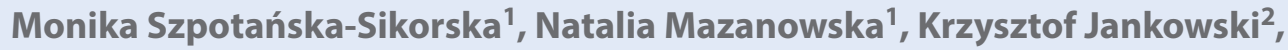 \\ Barbara Lichodziejewska ${ }^{2}$, Dorota Bomba-Opoń ${ }^{1}$ \\ ${ }^{1} 7^{\text {st }}$ Department of Obstetrics and Gynaecology, Medical University of Warsaw, Poland \\ ${ }^{2}$ Department of Internal Medicine and Cardiology, Medical University of Warsaw, Poland
}

\section{INTRODUCTION}

Pulmonary hypertension $(\mathrm{PH})$ is a rare condition with a high incidence of maternal and perinatal mortality (30-56\% and $10-13 \%$, respectively). Pulmonary hypertension is a contraindication to pregnancy because of high risk of maternal death, therefore the World Health Organisation (WHO) advises to discuss a termination in the event of pregnancy with women suffering from $\mathrm{PH}$.

\section{CASE REPORT}

A 34-year-old primigravida was admitted due to new-onset dyspnoea, fatigue and central cyanosis. Medical history was non-contributory: she denied prior cardiopulmonary diseases and any signs or symptoms suggestive of cardiac abnormalities. However, since the beginning of the $2^{\text {nd }}$ trimester of pregnancy she has complained of a non-productive cough, intensified by exertion.

The transthoracic echocardiography revealed a mitral valve thickening with limited cusps mobility. An estimated mitral valve area was $1.1 \mathrm{~cm}^{2}$, with peak and mean diastolic gradients across the valve 29 and $17 \mathrm{~mm} \mathrm{Hg}$. Left ventricular ejection fraction was $60 \%$. The tricuspid regurgitation pressure gradient (TRPG) reached $80 \mathrm{~mm} \mathrm{Hg}$. Distended vena cava inferior was detected and right ventricular systolic pressure (RVSP) reached $100 \mathrm{~mm} \mathrm{Hg}$. The patient was diagnosed with severe $\mathrm{PH}$ secondary to severe mitral stenosis. Therapy with $40 \mathrm{mg}$ furosemide was administered once daily. Percutaneous mitral valvuloplasty was considered, however, due to relatively stable condition it was not performed during pregnancy. The patient was in a stable general condition but presented a high risk of a pulmonary oedema and tachyarrhythmias with possible deterioration of patients' condition.

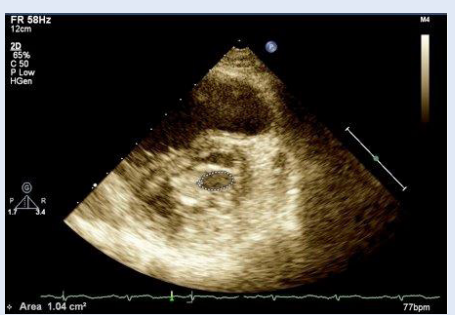

Figure 1. Third trimester of pregnancy. Two-dimensional echocardiography, the parasternal short-axis view. Thickened mitral valve leaflets. A planimetric measurement of mitral valve area. Mitral stenosis

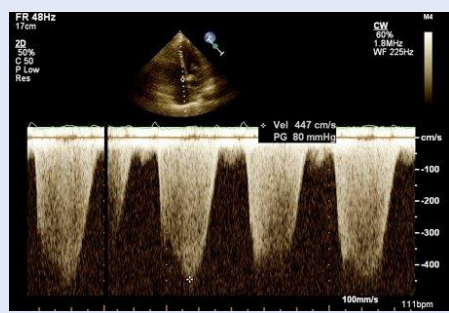

Figure 2. Tricuspid regurgitation used to estimate right ventricular pressure. Peak gradient (PG) calculated using the formula $4 \mathrm{~V}^{2}$

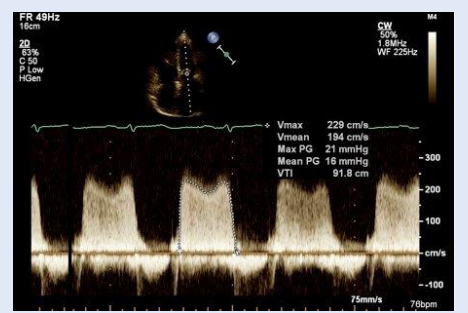

Figure 3. Echocardiography on the $6^{\text {th }}$ day after delivery. Slightly lower peak (maxPG) and mean (meanPG) gradients across the mitral valve

Corresponding author:

Monika Szpotańska-Sikorska

$1^{\text {st }}$ Department of Obstetrics and Gynaecology, Medical University of Warsaw

Starynkiewicza Sq. 1/3, 02-015 Warsaw, Poland

tel.: +48698676551

e-mail: mszpotanska@wp.pl 


\section{Perinatal management and neonatal outcome}

The antepartum cardiotocography as well as the ultrasound examination did not reveal any anatomical abnormalities nor biometric anomalies of the foetus. The antenatal corticosteroid therapy was prescribed. Subsequently in the $34^{\text {th }}$ week of gestation an elective caesarean section in general anaesthesia was performed, throughout the surgery she was hemodynamically stable. A healthy female newborn was delivered.

The woman's postoperative course was uneventful. The therapy with oral diuretics was continued with beta-blocker and potassium supplementation. An anticoagulant prophylaxis with enoxaparin sodium injections was administered. The postoperative echocardiography demonstrated lower peak and mean gradients across the mitral valve: 21 and $16 \mathrm{~mm} \mathrm{Hg}$, respectively and markedly decrease of TRPG $-48 \mathrm{~mm} \mathrm{Hg}$ and RVSP $-60 \mathrm{~mm} \mathrm{Hg}$. A tricuspid annular plane systolic excursion was $18 \mathrm{~mm}$. The mother and baby were discharged on the $9^{\text {th }}$ postoperative day.

\section{CONCLUSIONS}

Asymptomatic women suffering from $\mathrm{PH}$ might become symptomatic in advanced pregnancy. The optimal timing of delivery may lead to better maternal and neonatal prognosis, therefore the combined therapy and a mode of the delivery should be carefully considered by a multidisciplinary team. 